\title{
The report of investigation primary school and lower secondary school education informatization in Leshan city
}

\author{
Qianjun Tang, Jitka Laitochova, \\ David Nocar, Liang Mengjiao
}

\begin{abstract}
As the project team continuous researched for Sichuan province comprehensive reform pilot project of the 2 nd that is "depth integration of modern education technology into the primary and lower secondary school education pilot", we investigated the education informatization in 5 representative schools in the area of pilot launched a pilot area. We mainly focused on the sample school education informatization of hardware and software environment, teachers' skills of information technology, the usage of information resources and the education media, and teachers' awareness and attitude of information technology in education. For data collection we mainly adopted questionnaire, interview and visit three ways for data collection. Through the data collected in detail, quantitative analysis and qualitative analysis, we drew the corresponding conclusion about the various aspects above.
\end{abstract}

Keywords: the education of primary and lower secondary school, education informatization, information technology, the skills of information technology, training teacher. 


\section{Introduction}

To continue to research the 2 nd pilot comprehensive education reform project in $\mathrm{Si}$ chuan province in depth integration of modern education technology into the primary and lower secondary school education, the project team needs to know the situation of the pilot schools which are hardware and software of, the teachers' skill of ICT and the attitude and awareness towards ICT. In January 2016, the project team did an investigation in some schools in the pilot area: Shanwan district, Leshan city.

\section{Design of the Investigation}

In order to acquire the exact and full data about primary and lower secondary school informatization, my colleagues and I prepared and design the investigation very carefully and thoroughly. We together discussed the time, the sample of schools, the teachers from the sample school and our main aim in the investigation.

\subsection{Content and Objective of the Investigation}

Why do we investigate? It is the first thing we must think about carefully before we entered the schools. We wanted to know about the hardware, the software, the digital resources, the information situation and the attitude of the teachers in the pilot school.

\subsubsection{The Basic Informatization Situation in the Schools}

We wanted to know about the hardware and software of the schools, such as the schools' address, scale, faculty and the ranking in the area etc. For the hardware, we needed to know the campus website's input width and output width, the amount of the computer room, the performance of the computers, the ratio of student and computer, the amount and the performance of multimedia classroom, the hardware of the office, the performance of the campus website server. About the software, we needed to know the office-automatic and the instruction resources.

\subsubsection{The Situation of Usage of Hardware and Software}

The frequency of usage of computer room and multimedia classroom, application ICT in prepared lessons, class lessons, homework and tutorship, evaluating the students, and management, etc. were all cared about in this investigation. 


\subsubsection{Status of Teachers' ICT Skills}

We planned to investigate the situation of ICT applied by teachers, such as media routine application, computer and internet usage (information filtering and selection), basic units of MS and specific curriculum software apprehension. Part of this information can be collected from teachers' interviews, whereas the other by questionnaires in which the data is analyzed through the quantitative method.

\subsubsection{Teachers' Attitude and Perception towards educational informatization}

How teachers evaluate the educational informatization, and what are the advantages and disadvantages of the educational informatization.

\subsection{Sample selection}

In accordance with the presentation above, we take school as the sample unit. Referring to the objective requisite, we employed the principle as follows, primary schools mostly and lower secondary schools within obligatory education period, balance with urban and suburban schools. Regarding the quantity consideration, all the work load, difficulties, competence of researchers, 4 primary schools and more (including 2 urban ones, 2 suburban ones), 3 lower secondary schools and more (including 2 urban ones and 1 suburban one), which are supposed to be paid more attention. Additionally, 9 year-obligatory schools are prior to be selected, which can keep the sample capacity along with unloading the study stuff. As the participants of the primary schools, they are the urban schools of Shawan primary school and Fenghuang primary school, the other participants of the primary schools, they are the suburban primary schools of Jianong and Bishan. The 3 participant elementary schools are respectively Fenghuang, Suishan and Bishan. Furthermore, the Fenghuang and Bishan are the 9-years obligatory schools.

When doing the questionnaires for pursuing the data of teachers ICT skills, individual's characteristics cannot be neglected, for instance, age, teaching experiences, gender, subjects, education degree etc. Proportion of the sample attributes are aligned with the proportion of the teachers in the schools. 150 questionnaires are separately allocated to five schools, it means each school takes 30.

Moreover, in the process of data collection which pertains to the present situation of the ICT applying, in spite of campus tour and investigation by the means of questionnaires, and another approach seeking information is through additional two questionnaires and in-deep interviews from the teachers. 
For the aspect of the attitude and perception, data collection is mainly by the interviews. 5-10 persons are selected randomly, while some sample index as teaching subjects, sex, age and so on, which should be taken into consideration.

\subsection{Data Collection}

Questionnaires, visual and record along with the interviews, photos, all are the ways employed of collection. Need to say that all the audio-video record is accredited by the interviewees.

\section{Data Analysis}

Collection data took us more than three days, however, the great deal of hard work lied in how to analyse the data. We needed to clear the photos, the questionnaires, the notes of the interview; in fact, the hardest work was transition the audio, video into text. For example, one hour audio or video clip would take me ten hours to write down the words, and there would be more than 40,000 words.

\subsection{Environment of School Educational Informatization}

In this section, we focus on the environment of pilot schools information. I will analyse the basic information, their hardware, the digital educational resources and the software applied in the pilot schools.

\subsubsection{Status of School ICT}

It is revealed that school ICT teachers are less than presupposition and elder than the average, from the perspective of teacher body. As Fenghuang school, there are 4 ICT teachers, take up $3.3 \%$ of the whole faculty and staff, nonetheless only one is under 35 years old compared with the others. Thus, it is conveyed that it's not easy for them to learn ICT if they are elder. On the other hand, all the ICT teachers are neither from the professional major of computer science nor education technology, while they are transferred from other positions due to the individual interests.

\subsubsection{Hardware Environment}

Study shows that all the classrooms of the 5 participant schools are the multi-media classrooms which are equipped with whiteboard and video presenter. Every school 
has the separate computer room with 228 advanced computers, which occupies the $45 \%$ of the total. Computers belong to teachers use only, there are 159 computers in the 5 schools. Fenghuang has 83 computers including 23 advanced ones, which take up $26.3 \%$ of the whole. There are 159 computers for the staff use only of all the 5 participants, including 4 advanced, which is $6.9 \%$ of the total.

Consequently, it is acknowledged that they have a plethora of computers, but old-fashioned. They reported that the high expenditure of maintenance is out of their reach, for the projector using frequently, bulb tired too fast to project clearly; for the whiteboard, touch site inaccuracy resulted from the long-time use, which made slow response, etc.

It can be conveyed that the 3 of the 5 schools have the server and computer wardrobe, whereas only 2 of them has the campus website, in which the information transmitting is limited. Therefore, the web construction is not as good as it is supposed to be, for $40 \%$ of the total without campus website, while they only employed the basic function even with the access to the campus net.

Cardinal approach of transferring the message and information, campus website, facilitate teaching in the classrooms. It is seen that campus website plays the profound role in the education informatization process.

\subsubsection{Resources}

It can be described that computer applied of the 5 participants is all out of the internet, which means they can use Office software only. Moreover, plenty of resources which are used for teaching are available in the schools. Conversely compared with the usage for instruction, there is less for students use, such as Suishan lower secondary school with the database of $2 \mathrm{G}$. Most resources of the participants are attributed to download, such as Shawan primary school usage more of download resources, see figure 3.1.

Figure 1

The Source of the Education Resources

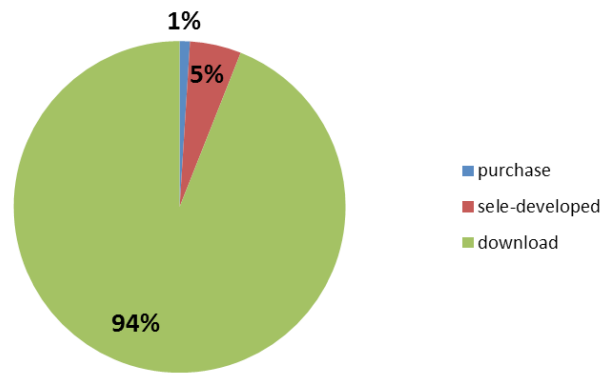


Above all, it revealed the unbalance of the resources employment, actually there is less resources that can be shared with student, thus it is expected the development of the resources in the future.

\subsubsection{Hard-Soft Ware}

Computer-rooms are used with high frequency, for example, there are 102 computers in Fenghuang school which are used 1300 times, and each computer is used 12.7 times per week. Multi-Media classrooms are fully made use of, there are 115 classrooms in the 5 schools, which are used for 2545 classes per week.

Teachers are able to apply ICT in teaching, for example, preparation which is processed by PPT, editing of teaching plan, data searching, etc. and in the sense of homework and instruction, ICT is applied in research and homework revision. To some extent, ICT is permeated in the communication amongst teachers, students and parents, normally as QQ, Wechat and so on.

As the aspect of school management, only 1 of 5 own its management system, while ICT with the management as well as the QQ, Wechat, etc. However, ICT is completely employed in the tests statistic, which is covered by MS Office.

Accordingly, frequency of ICT usage is comparative high in 5 schools along with the frequently using by teachers, while which all are within the junior level of ICT.

\subsection{Teachers' ICT Capacities}

The survey used questionnaires to investigate the teachers'ICT capacities, including the usage of ordinary media, manipulation of computers, and ability of website operation, information searching and filter, 3 basic Office software comprehension, perceiving special curriculum software.

Questionnaires were sent to 2 primary schools (Shawan and Jianong primary school), 2 9-year obligatory schools (Fenghuang and Bishan schools) and 1 lower secondary school. Each school deserves to have 30. Proportion of sex, age and subjects which are of the indexes are deliberately attended among the participants during the survey. 143 questionnaires are allocated aligning with the returns, however, 142 are valid, and validity is $99.3 \%$. Data is processed by Excel.

Questions in the questionnaire contribute to 6 categories and 15 questions, they are constituted by the questions as follows. 2 questions for ordinary media usage, 6 questions are computer manipulation and special curriculum software apprehension, 3 questions refer to website and information searching and filter relevance, 2 questions posed on the attitude and perception of teachers, 1 question is about ICT capacities development of teachers. 


\subsubsection{Ordinary Media Usage}

The question focuses on usage of conventional media by the primary and lower secondary schools' teachers. See figure 2.

\section{Figure 2}

Percentage of Skillfully Operate Conventional Device

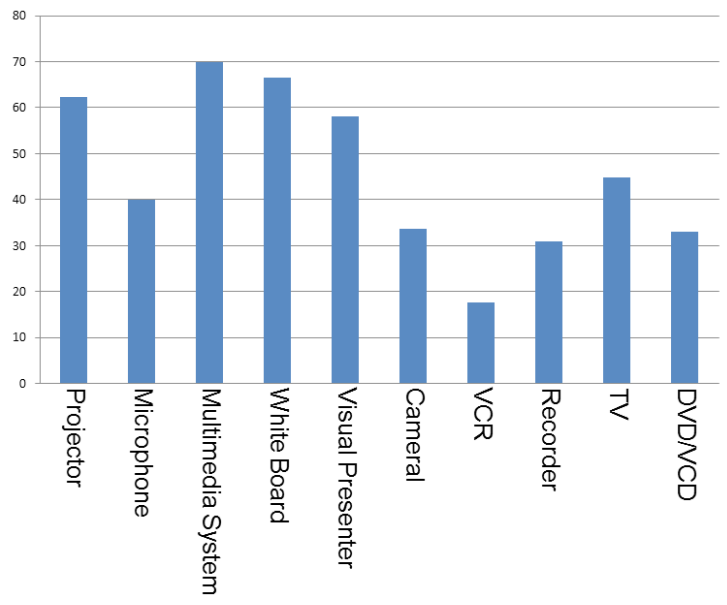

Statistics demonstrates that it's not a sufficient employment. Projector, multimedia system, whiteboard are comparatively well applied, multimedia utilization up to $69.9 \%$, video presenter is $58 \%$, which are all thanks to the promotion and popularization of multimedia system, but there is still need for further development. On the other hand, the utilization of microphone, camera, VCR, recorder, DVD player is not good, especially the worst of VCR, which refers to much reduction of conventional media employment.

What's more, it is portrayed that fewer teachers can use the media instruction system proficiently, on the other side, most of them are average users and even lower than average ones. There's no doubt that it need developing better and better. 


\subsubsection{Manipulation of Computer and Special Curriculum Software Apprehension}

See figure 3 below.

\section{Figure 3}

Basic Operation of Computer

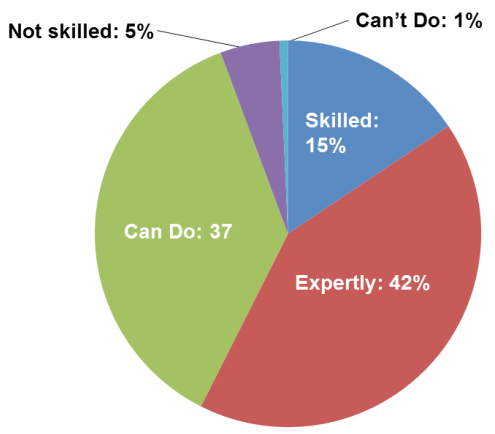

It is revealed that the manipulation and control of computer and special software is under expectation. Proficient level and equivalence is $56.7 \%$, even though the basic manipulation of computer is the cornerstone of the teaching informatization and further education of informatization, nearly half of them evaluated themselves under the level of average.

See figure 3.4 for the frequently used software below.

\section{Figure 4}

The Frequency of Use Software

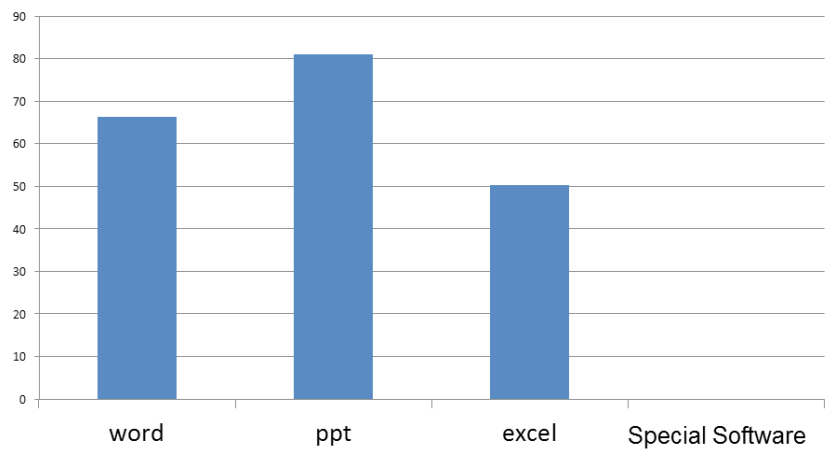


Office software is the normal used one in teaching and learning of teachers, which reflect the degree of teachers' informatization straightforwardly. In addition, study statisticly showed that the comprehension of the special instruction software is zero.

See figure 3.5 which refers to the coherent courseware.

\section{Figure 5}

Percentages of Search Resources during Instruction

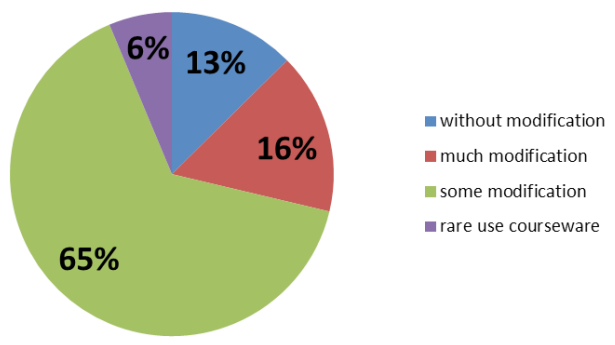

It is seen that most materials are used after some modification, while much more modification takes up $16.1 \%$, which is not too much. However, the proportion of without modification is up to $12.6 \%$ indeed. All that mean that content, display and style of the multimedia courseware used by teachers are similar basically, and in other words, what belong to the idiosyncrasy of teachers turns less and less.

\subsubsection{Website Utilization and Information Searching and Filter}

Figure 6 is about web resources utilization, see below.

Figure 6

Web Resources Utilization

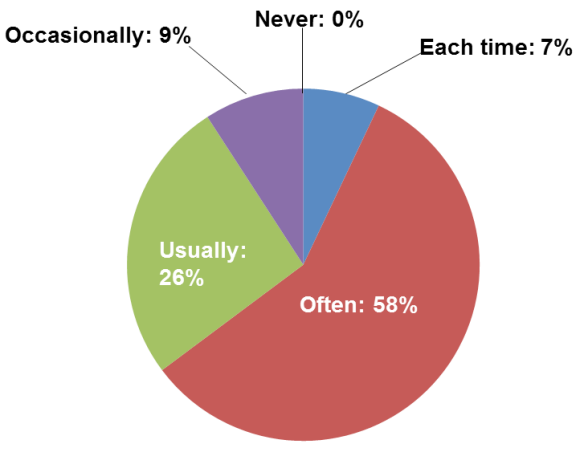


About $64 \%$ of the teachers seeking information on-line in terms of the research statistics, and nearly $89 \%$ teachers use internet searching information in work. It is implied that most teachers make use of the internet for pursuing education resources. Furthermore regarding the aspect of searching and filter of internet resources, $63.7 \%$ teachers attained their goals of searching through the internet in the light of the data analysis, while the rest $36.3 \%$ of the whole teachers are not able to download their resources successfully.

\subsection{Perception and Attitude of Teachers towards ICT}

Interviews are utilized to collect the data about the aspect of perception and attitude of teachers, in accordance with interviewees' permission, we use 3 different ways, taking down notes, VCR and audio record of collection. 5-10 persons were selected from each school accompanied with the consideration of teaching subjects, sex and age, etc. 29 persons were involved in the 8 times' interviews, especially ICT teachers from Shawan primary school, Biwhan and Fengwuang schools respectively, take the special interviews. Data of VCR and audio record converted into 20,000 words text, which is mainly about the content of the advantages and disadvantages of ICT using in their daily routine, what is need to improve and suggestions on the ICT skill training for school teachers.

\subsubsection{Attitude towards ICT in Education}

26 out of 29 interviewees are positive in utilization of ICT and ordinary media, they thought it is intuitive and easy, as figure 3.7 demonstrated. Mathematics teachers prefer graphic technology of multimedia. As Teacher Lian from Bishan school put it, "Through the graphic technology, problems about symmetry axis, parallel to the rotation, strong model of 3-Dimension, reflection of the shadow and so on are all well in use." Chinese and English teachers thought it helps the context construction be smoothly, as which is mentioned by Chinese Teacher Zhao of Fenghuang school, students read the text with the music that is downloaded from the internet; English Teacher Ji said that the prominent advantage of the multimedia was expressed on the repeat and pronunciation; Chemistry Teacher Li said three advantages of ICT in chemistry teaching, first is about intriguing students by display something normal in reality, secondly it can transfer microscopic process of the molecule and atom into macroscopic one, thirdly it can be present easily for the dangerous experiment by simulation on video. 
Figure 7

The Significance of ICT in Education

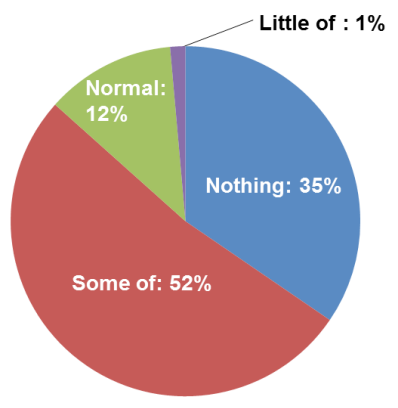

Conversely, part of them mentioned the aspect of disadvantages, such as the information is too rich to grasp the point for students, and it is too fast to remember, even without making deep thinking. Especially, most of them were worried about students' vision, which was influenced by long time looking at whiteboard. For example, Teacher An of Jianong primary school said that she was taking some negative attitude towards the multimedia, she thought that students looked at the whiteboard all the day while they cannot get a rest if they continue to watch the TV after school, which did harm to their vision. Additionally, Chinese Teacher Yu thought it really has uses but not many, esp. for Chinese learning, courseware as PPT can stifle the imagination of students. Mathematics Teacher also agreed that students were all too concentrated on the courseware to think by themselves, esp. for deviation in mathematics, to some extent that students were just waiting for the spontaneous result without any insightful exploration and thinking.

Whatever positive or negative attitude towards ICT, the point is that teachers use ICT frequently including ordinary multimedia, as Fine Arts Teacher Li of Shawan primary school said that all the classes were conducted with computer and whiteboard except physical education. Teachers search relevant materials from the internet or coherent e-resources before class, furthermore two-thirds of teachers use the material in class after their modification.

\subsubsection{ICT Training}

Interviewees talked less on this issue. However, firstly they all had the will to take part in the ICT training program, even 3 of them over 50 years old still want to be involved (Tang q., 2015). In addition, most teachers haven't defined the content of ICT training, only 2 mathematics teachers mentioned the operation of the sketchpad, as figure 3.8 displayed. Thirdly, they wish it is school-based training, which is easy for them to 
balance learning and working and expanding benefits. Chinese Teacher Zhou from Shawan primary school said:"I don't like to attend the training outside when I am teaching, I cannot focus on the training because of worrying about my students. Moreover, the schedule of training should be flexible, especially not during the weekends. The content of the training shouldn't be too much and complicated as such, it is better of one theme per time for me."

Figure 8

The Percentage of Training Content

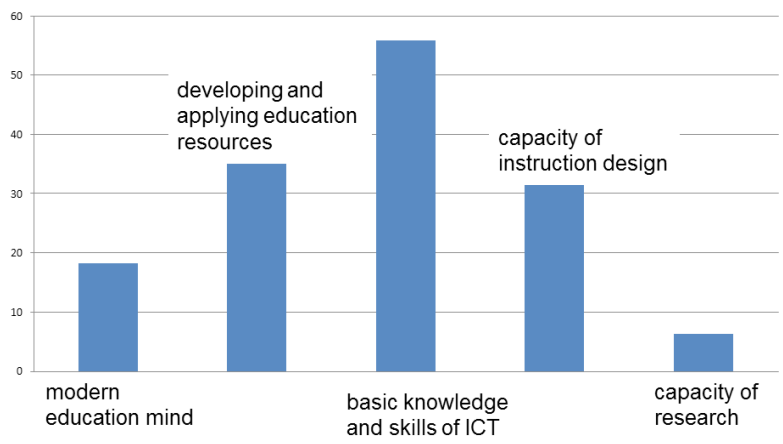

\section{Conclusion}

Based on the analysis detail above, we will draw some conclusions. According to the aim of the investigation and our analysis, we can acquire some results related to the hardware and software environment, the teachers' ICT capabilities, and the attitude and awareness in the pilot schools.

\subsection{Hardware Environment}

Each school in Shawan district has an access to 20-50 optical broadband which accomplished campus website coverage system, along with 341 each-class-availableresources-33 computers rooms, 27 e-classrooms for preparation lessons, 9 multimedia classrooms based on subarea, 4 active PR classrooms, 23 systems of laboratory management, 23 types of campus easy radios and 40 LED displays.

While part of the equipment is worn out, for instance, inaccurate positioning of whiteboard, old used light bulb of the projector, frequent crashing of computer when 
recording micro-lecture. Indeed, the effect of focus and light of the video presenter is not good enough; some problems of switching signal on the controller in the multimedia classrooms are raised, which demonstrated that teachers would rather control presenter by computers; as for the LED whiteboard, 65 inches' is not big enough within the reach of more than 50 students, students at the back cannot see it clearly.

\subsection{Software Environment}

Most schools share the resources through the collective preparation lessons, that are fabulous, whatever the resources from collection or self-developed, which are shared together. As the reference CDs are well applied by music and mathematics teachers.

However, national basic education repository and other resources from the internet are not compatible with teaching perfectly, although they are rich while not appropriate, and some of them are no match to the teaching materials. Actually, regional educational repository is developing in Shawan District at the beginning, while teachers have strong urge to pursue appropriate resources for teaching. Situation of building and utilization of campus website is not optimistic as well, which will affect sharing resources and posting information.

\subsection{ICT Capacities of Teachers}

Teachers had a good command of the ordinary media, esp. basic computer operation, they often utilized multimedia for teaching, most teachers got resources through the function of searching and filter, most teachers applied the download resources into teaching after modification, and part of teachers can develop their own courseware for class.

As for instruction media whiteboard, they are regarded as displayer devices and are not full used their profound functions. The teachers can't coordinately or skillfully operate the traditional instruction media, even can't operate at all. They rarely analyze data with simple software for example MS-Excel, many of them only can calculate Average, Sum, and the peak. However, the relationship-analysis or the regression-analysis is not heard at all.

\subsection{The Attitude and Awareness about ICT}

Nearly all teachers think that the role of ICT is very important in education, and their workload is decreased by ICT, and students' interest is enhanced. Multimedia can help context construction smoothly, and transition microcosmic into macroscopic (MoE of China, 2014). The teachers have strong interest in ICT and hope to attend trainings to continue study more skills of ICT. 
On the other hand, many teachers worry about their students' eye-sight affected for widely using whiteboard in every school, even in every class from morning to evening. Some teachers think that widely used ICT can be used as a simulation that will affect or even kill student's imagination, and over depend on the ICT will make the student too idle to think. Some teachers think knowledge is too much to understand in so short time, and the knowledge is displayed too soon to understand clearly the process.

\section{Acknowledgements}

This paper was written as part of a specific research project of the Faculty of Education, University of Palacky (grant number IGA_PdF_2016_009) The Situation of ICT in Primary School in Olomouc and in Leshan City.

Additional, this paper has been funded by The $2^{\text {th }}$ Pilot Comprehensive Education Reform Project in Sichuan Province - Depth Integration of Modern Education Technology into the Primary and Lower Secondary School Education.

\section{References}

Tang Qianjun. (2015). A Report of Survey Analysis the Primary and Middle School Teachers'Information Technology Application Ability. Journal of Leshan Normal University, 2015(02): 136-140.

Ministry of Education. (2014). China. The Criteria of Application ICT for Middle School and Primary School Teacher.

\section{Contact:}

Qianjun Tang,

Leshan Normal University, China

E-mail: 57225351@qq.com

Jitka Laitochova

E-mail: jitka.laitochova@upol.cz

David Nocar

E-mail: David Nocar@upol.cz

Liang Mengjiao

E-mail:251460710@qq.com

Faculty of Education, Palacký University

Žižkovo nám. 5, 77140 Olomouc

Czech Republic 